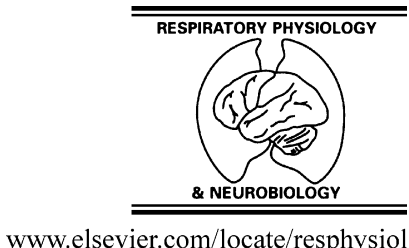

\title{
The role of NADPH oxidase in carotid body arterial chemoreceptors
}

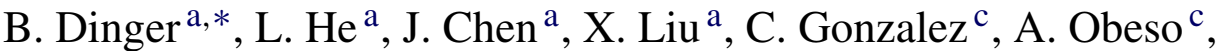 \\ K. Sanders ${ }^{b}$, J. Hoidal ${ }^{\text {b }}$, L. Stensaas ${ }^{\text {a }}$, S. Fidone ${ }^{a}$ \\ ${ }^{a}$ Department of Physiology, University of Utah, School of Medicine, USA \\ ${ }^{\mathrm{b}}$ Department of Internal Medicine, University of Utah, School of Medicine, USA \\ ${ }^{c}$ Departamento de Bioquimica y Biologia Molecular y Fisiología, Instituto de Biologil̆a y Geně̌tica Molecular Facultad de Medicina, \\ Universidad de Valladolid y Consejo Superior de Investigaciones Cientı̌̆ficas, Valladolid, Spain
}

Accepted 10 December 2006

\begin{abstract}
$\mathrm{O}_{2}$-sensing in the carotid body occurs in neuroectoderm-derived type I glomus cells where hypoxia elicits a complex chemotransduction cascade involving membrane depolarization, $\mathrm{Ca}^{2+}$ entry and the release of excitatory neurotransmitters. Efforts to understand the exquisite $\mathrm{O}_{2}$-sensitivity of these cells currently focus on the coupling between local $\mathrm{P}_{\mathrm{O}_{2}}$ and the open-closed state of $\mathrm{K}^{+}$-channels. Amongst multiple competing hypotheses is the notion that $\mathrm{K}^{+}$-channel activity is mediated by a phagocytic-like multisubunit enzyme, NADPH oxidase, which produces reactive oxygen species (ROS) in proportion to the prevailing $\mathrm{P}_{\mathrm{O}_{2}}$. In $\mathrm{O}_{2}$-sensitive cells of lung neuroepithelial bodies (NEB), multiple studies confirm that ROS levels decrease in hypoxia, and that $E_{\mathrm{M}}$ and $\mathrm{K}^{+}$-channel activity are indeed controlled by ROS produced by NADPH oxidase. However, recent studies in our laboratories suggest that ROS generated by a non-phagocyte isoform of the oxidase are important contributors to chemotransduction, but that their role in type I cells differs fundamentally from the mechanism utilized by NEB chemoreceptors. Data indicate that in response to hypoxia, NADPH oxidase activity is increased in type I cells, and further, that increased ROS levels generated in response to low- $\mathrm{O}_{2}$ facilitate cell repolarization via specific subsets of $\mathrm{K}^{+}$-channels.
\end{abstract}

(c) 2006 Elsevier B.V. All rights reserved.

Keywords: Control of breathing; Peripheral chemosensitivity

\section{Introduction}

The survival of multicellular aerobic organisms is dependent on a continuous supply of molecular oxygen. $\mathrm{O}_{2}$ is consumed in enzymatically catalyzed electron transfer reactions which occur in cell membranes, at multiple sites throughout the cell, and within particular organelles, such as mitochondria. Much of the $\mathrm{O}_{2}$ used in these reactions is completely reduced via the transfer of four electrons to form two molecules of $\mathrm{H}_{2} \mathrm{O}$. However, important amounts of $\mathrm{O}_{2}$ can also be partially reduced, by single electron reduction to form the highly reactive metabolite, superoxide anion $\left(\mathrm{O}_{2}{ }^{-}\right) \cdot \mathrm{O}_{2}{ }^{-}$is converted to hydrogen peroxide

\footnotetext{
* Corresponding author at: Department of Physiology, University of Utah, 420 Chipeta Way, Suite 1700, Salt Lake City, UT, USA. Tel.: +1 801581 8488; fax: +1 8015813476 .

E-mail address: b.dinger@utah.edu (B. Dinger).
}

$\left(\mathrm{H}_{2} \mathrm{O}_{2}\right)$ by an isozyme of superoxide dismutase (SOD) either in the cytosolic compartment ( $\mathrm{ZnCuSOD)}$ ), or in mitochondria (MnSOD). In the presence of transition metal ions, $\mathrm{O}_{2}{ }^{-}$ can also undergo conversion to the highly reactive hydroxyl radical $\left(\mathrm{OH}^{-}\right)$(Thannickal and Fanburg, 2000). These partially reduced metabolites of $\mathrm{O}_{2}$ have been designated "reactive oxygen species" (ROS) because they are variously more reactive than molecular $\mathrm{O}_{2}$. High levels of ROS have traditionally been regarded as toxic (oxidative stress), and their numerous potentially damaging effects collectively constitute the basis for one of the most popular theories of aging. However, recent investigations have also demonstrated that low concentrations of ROS, produced locally and acting on nearby effectors, are important signaling molecules (Thannickal and Fanburg, 2000; Sauer et al., 2001; Griendling et al., 2000; Lambeth, 2002; Finkel, 2000). Thus, an emerging body of data indicate that specific extracellular stimuli including cytokines, neurotransmitters and hypoxia initiate signaling cascades involving the production of 
ROS from mitochondria and non-phagocyte forms of NADPH oxidase (Chandel and Schumacker, 2000b; Thannickal and Fanburg, 2000). Like cyclic nucleotides (cAMP, cGMP), inositol phosphates $\left(\mathrm{IP}_{\mathrm{N}}\right)$ and nitric oxide (NO), ROS affect specific targets within local cellular compartments (Pani et al., 2001), frequently involving select cysteine and methionine residues which are highly labile for oxidation/reduction (Thannickal and Fanburg, 2000; Xu et al., 2002). Changes in the redox state at these sites has been demonstrated to critically alter important effector molecules such as ion channels $\left(\mathrm{K}^{+}\right.$-channels (Hoshi and Heinemann, 2001; Tang et al., 2001)), protein kinases (Thannickal and Fanburg, 2000) and transcription factors (HIF$1 \alpha$, NF-кB, AP-1 (Thannickal and Fanburg, 2000; Görlach et al., 2001; Zhu et al., 2002; Chandel and Schumacker, 2000b)).

\subsection{ROS formation in mitochondria}

Mitochondrial cytochrome oxidase catalyzes the fourelectron reduction of $\mathrm{O}_{2}$ in the final step of an elaborate electron transport chain which captures metabolic energy in the terminal phosphate bond of ATP. In addition, $1-3 \%$ of the $\mathrm{O}_{2}$ consumed by mitochondria is partially reduced to $\mathrm{O}_{2}{ }^{-}$by enzyme-complex I, the ubisemiquinone site of complex III, and other electron transfer proteins (Chandel and Schumacker, 2000b; Thannickal and Fanburg, 2000). Extended periods of hypoxia (1-2h) may depress the $V_{\max }$ of cytochrome oxidase, and produce a shift in the redox state within mitochondria (i.e., increased levels of NADH), thereby promoting the formation of $\mathrm{O}_{2}{ }^{-}$(Chandel and Schumacker, 2000b). Although its negative charge prevents this anion from crossing mitochondrial membranes, it is rapidly converted by MnSOD to highly membrane permeant $\mathrm{H}_{2} \mathrm{O}_{2}$ (Sauer et al., 2001), which appears to mediate apoptotic signaling and cell proliferation (Irani, 2000). Mitochondria have also been implicated as cellular $\mathrm{O}_{2}$ sensors in erythropoietin (Epo)-producing Hep3B cells and pulmonary artery smooth muscle cells. Mitochondrial ROS production evoked by hypoxia has been correlated with modulation of $\mathrm{K}^{+}$-channels and vasoconstriction (hypoxic pulmonary vasoconstriction, HPV (Michelakis et al., 2002; Chandel and Schumacker, 2000b; Waypa et al., 2001)). However, the mechanism by which mitochondrial ROS are coupled to contractile elements has not been elucidated, and the role of cell redox in HPV is a point of considerable controversy (Sylvester, 2001).

\subsection{ROS formation by NADPH oxidase}

For many years it has been known that large quantities of ROS are produced by phagocyte cells as part of an extracellular killing mechanism activated in response to invading micro-organisms. ROS-generating phagocyte NADPH oxidase is a complex enzyme comprised of two trans-membrane and four cytosolic subunits (Fig. 1). The large $91 \mathrm{kDa}$ glycoprotein (gp91 ${ }^{\text {phox }}$; phox: phagocyte oxidase) and a $22 \mathrm{kDa}$ protein (p22 ${ }^{\text {hox }}$ ) form a membrane bound cytochrome b558 (Sauer et al., 2001; Diebold and Bokoch, 2001; Babior, 1999). Immunologic stimulation initiates a protein kinase C (PKC)-dependent process in which the cytosolic subunits $\mathrm{p} 67^{\text {phox }}, \mathrm{p} 40^{\text {phox }}, \mathrm{p} 47^{\text {phox }}$

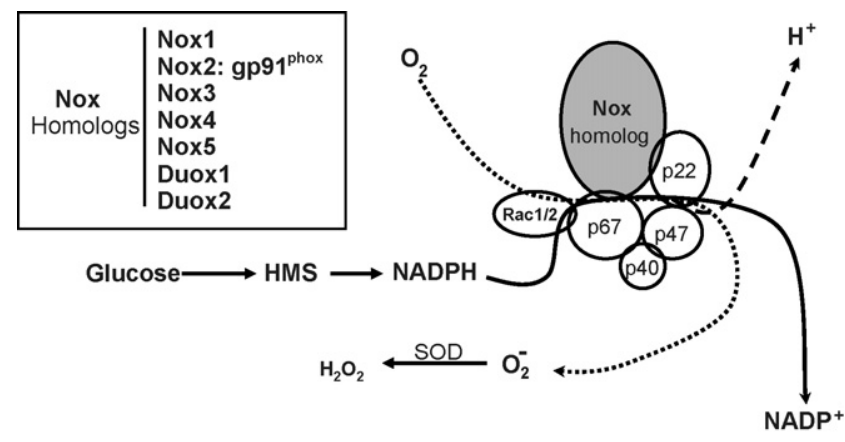

Fig. 1. Composition and function of NADPH oxidase (Nox). A heme-containing Nox-homolog plus p22 $2^{\text {phox }}$ form a cytochrome b558 which in the phagocytic enzyme is embedded in plasma membrane. Cytosolic components [p67 ${ }^{\text {phox }}$, $\mathrm{p} 47^{\text {hox }}, \mathrm{p} 40^{\text {phox }}$, plus a GTPase (Rac 1 or 2)] transmigrate in a protein kinasedependent process to form the functional enzyme. The cofactor, NADPH, is formed in the hexose monophosphate shunt (HMS) pathway of glucose metabolism. Superoxide anion, $\mathrm{O}_{2}{ }^{-}$, is converted to hydrogen peroxide $\left(\mathrm{H}_{2} \mathrm{O}_{2}\right)$ by superoxide dismutase (SOD). Inset indicates various superoxide-generating Nox homologs (Nox 1-5) which may be associated with membranes, organelles or cytoskeletal components. Duox 1 and Duox 2 function as hydrogen ion transporters.

and a small GTPase (Rac-1 or Rac-2), unite at the membrane to form the active enzyme. An electron is then transferred from NADPH (produced in the hexose monophosphate shunt pathway [HMS] of glucose metabolism) to $\mathrm{O}_{2}$, thus forming $\mathrm{O}_{2}{ }^{-}$ plus $\mathrm{NADP}^{+}$and $\mathrm{H}^{+}$(Babior, 1999; Diebold and Bokoch, 2001). Despite advances in demonstrating the importance of ROS in cell signaling, the role of the phagocyte oxidase is perplexing because it is inactive in resting cells, and produces $\mathrm{O}_{2}{ }^{-}$primarily on the extracellular side of the plasma membrane (Diebold and Bokoch, 2001), whose location is thus entirely inconsistent with the action of an intracellular messenger. However, recent studies of non-phagocyte cells have shown that NADPH oxidase may also be constitutively active, and produce ROS intracellularly at low levels (Brar et al., 2002b,a; Li and Shah, 2002; Szöcs et al., 2002; Görlach et al., 2001). For example, vascular endothelial cells contain an NADPH oxidase in which cytochrome b558 and the cytosolic subunits are preassembled on cytoskeletal elements in the perinuclear region, where they are engaged in constitutive production of intracellular ROS (Li and Shah, 2002). Moreover, recent studies in the lung have documented the involvement of ROS generated by NADPH oxidase in chemosensory cells of neuroepithelial bodies (NEB) which respond to hypoxia by inhibition of a voltage-dependent $\mathrm{K}^{+}$-current. Furthermore, $\mathrm{K}^{+}$channels in these cells are activated by low concentrations of $\mathrm{H}_{2} \mathrm{O}_{2}$, and hypoxia-evoked depression of channel activity is occluded in the presence of oxidase inhibitors, suggesting that ROS production is a key factor which couples local $\mathrm{P}_{\mathrm{O}_{2}}$ to cell activity (Wang et al., 1996). Importantly, the depolarizing response is absent in null-mutant mice lacking gp91 phox (Wang et al., 1996; O'Kelly et al., 2000; Fu et al., 2000a).

Homologs of gp91 phox (Fig. 1) have been cloned and sequenced from a variety of cell types, suggesting that there are multiple forms of the enzyme which are adapted to function in specific signaling pathways (Cheng et al., 2001; Lambeth, 2002). Some of these alternative forms of NADPH oxidase 
(Nox1-5, plus Duox1and Duox2) have likewise been proposed as $\mathrm{O}_{2}$-sensors which produce $\mathrm{ROS}$ in proportion to local levels of $\mathrm{P}_{\mathrm{O}_{2}}$ (Acker, 1994; Porwol et al., 2001). ROS generated by Nox homologs may also mediate cell proliferation and expression of transcription factors in multiple cell types (e.g., airway smooth muscle, melanoma cells, vascular endothelial cells (Brar et al., $2002 \mathrm{~b}$,a; Irani, 2000)) in response to a variety of physical (e.g., shear stress) and chemical (e.g., cytokines, neurotransmitters) stimuli (Griendling et al., 2000; Irani, 2000). Chemosensory type I cells in the carotid body, like NEB cells in the lung, are $\mathrm{O}_{2}-$ sensors which respond to acute hypoxia (AH) by depolarization, $\mathrm{Ca}^{2+}$ entry, the release neuroactive agents, and activation of sensory nerves. ROS have been proposed as intracellular mediators of chemotransduction events in type I cells, coupling momentto-moment cellular activity to the prevailing $\mathrm{P}_{\mathrm{O}_{2}}$ (Acker, 1994), but efforts to determine the precise mode(s) of involvement of Nox in ROS production have resulted in conflicting views (Obeso et al., 1999).

\section{Oxygen sensing in the carotid body and the potential involvement of ROS}

Exposure of the carotid body to AH elicits increased neural activity in the carotid sinus nerve (CSN), and reflex cardiopulmonary adjustments which mitigate the adverse effects of hypoxia. Increased carotid body activity occurs at low to moderate arterial $\mathrm{P}_{\mathrm{O}_{2}}$ levels, in contrast to the severe hypoxia required to elicit metabolic and functional adjustments in non$\mathrm{O}_{2}$ sensing tissues (Fidone et al., 1997, 1995; Gonzalez et al., 1994). Neuroectodermal type I cells are responsible for this exquisite sensitivity, and contemporary efforts to understand their unique hypoxic chemotransduction mechanisms have focused primarily on the relationship between $\mathrm{P}_{\mathrm{O}_{2}}$ and the activity of $\mathrm{K}^{+}$-channels (Gonzalez et al., 1994; Peers and Buckler, 1995; Lopez-Lopez et al., 1989; Lopez-Barneo, 1994; LopezBarneo et al., 2001). In the rat, studies of type I cells have demonstrated that hypoxia inhibits two types of $\mathrm{K}^{+}$-channel: (1) a large-conductance, voltage- and calcium-dependent channel (maxiK (Peers, 1990; Wyatt and Peers, 1995)), and (2) a voltageindependent TASK-type channel which mediates a background leak current (Buckler, 1997; Buckler et al., 2000, 2006). Available data indicate that TASK-like channels play a major role in setting the $E_{\mathrm{m}}$, and they strongly suggest that closure of these channels initiates cell depolarization (Donnelly, 1997; Buckler, 1999). The properties of maxiK, however, are not consistent with the initiation of cell activity evoked by hypoxia because their current-voltage characteristics suggest that they do not open until the membrane potential is more positive than $-20 \mathrm{mV}$. Because of these properties, and the fact that specific maxiK blockers fail to activate type I cells, some authors conclude that maxiK channels modulate cell activity and facilitate repolarization of the membrane (Prabhakar, 2000; Buckler, 1999; Donnelly, 1997). In this view, hypoxic inhibition of the maxiK current would contribute to cell activity by delaying recovery of the cell to the resting state.

There is general agreement that the $\mathrm{K}^{+}$-channels which are also expressed in non- $\mathrm{O}_{2}$ sensing tissues are not inherently

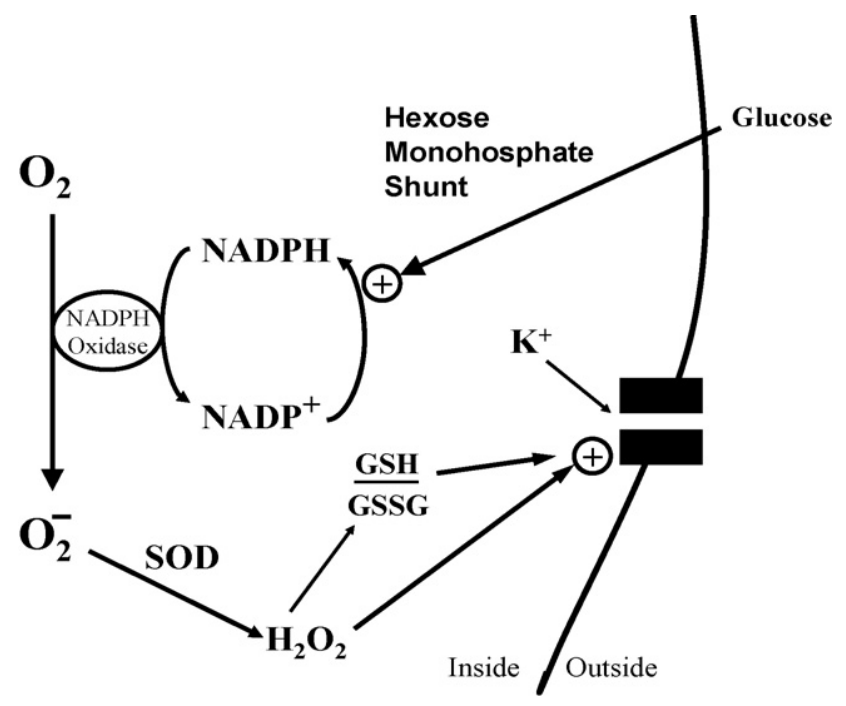

Fig. 2. Nox function in $\mathrm{O}_{2}$-sensitive chemoreceptor cells. Diagram depicts activation of $\mathrm{K}^{+}$-channel by $\mathrm{H}_{2} \mathrm{O}_{2}$, and/or shift in ratio of reduced (GSH) vs. oxidized (GSSG) glutathione (i.e., cellular redox potential). The rate of superoxide generation may depend on the concentrations of molecular $\mathrm{O}_{2}$, and/or NADPH cofactor produced by glucose flux through the hexose monophosphate shunt. SOD: superoxide dismutase.

sensitive to molecular oxygen and must somehow be coupled to responsive cellular components modulated by the prevailing $\mathrm{P}_{\mathrm{O}_{2}}$ in type I cells (Patel and Honoré, 2001). Foremost amongst the differing points of view regarding $\mathrm{O}_{2}$-sensing are that either an $\mathrm{O}_{2}$-binding heme-protein in the plasma membrane (Lopez-Lopez and Gonzalez, 1992), or specialized $\mathrm{O}_{2}$-sensitive cytoplasmic components (i.e., mitochondria or Nox (Acker, 1994; Wilson et al., 1994; Buckler et al., 2006)), modulate the activity of $\mathrm{K}^{+}$-channels. Importantly, a recent review by Prabhakar pointed out that these different mechanisms are not necessarily mutually exclusive, and that chemoreceptor cells may integrate signals from multiple $\mathrm{O}_{2}$-sensors, which collectively determine $\mathrm{K}^{+}$-channel activity (Prabhakar, 2000). This concept is particularly attractive because it also embodies the notion that hypoxia targets multiple cellular components, and that the response depends on both the severity and duration of the stimulus.

\section{Diverse views of Nox function in carotid body}

The Nox hypothesis of $\mathrm{O}_{2}$-sensing (Fig. 2) in type I cells suggests that a phagocyte Nox 2 or other isoform couples $\mathrm{P}_{\mathrm{O}_{2}}$ to $\mathrm{K}^{+}$-channel activity by generating ROS in proportion to available $\mathrm{O}_{2}$ (Acker, 1994). Accordingly, $\mathrm{H}_{2} \mathrm{O}_{2}$ derived from $\mathrm{O}_{2}{ }^{-}$ by the action of SOD would facilitate $\mathrm{K}^{+}$-channel activity either by direct action on channel protein or via a shift in the cell redox balance. Indeed, application of low concentrations of $\mathrm{H}_{2} \mathrm{O}_{2}$ to the in vitro rat carotid body/CSN preparation has been shown to depress chemoreceptor nerve activity (Acker et al., 1992), and a non-specific inhibitor of the oxidase, diphenyleneiodonium (DPI), alters nerve activity evoked by hypoxia (Cross et al., 1990). Furthermore, certain subunits common to the phagocyte and non-phagocyte forms of the enzyme, including 
p22 $2^{\text {phox }}$, gp91 $1^{\text {phox }}$ (or a closely related Nox isoform), p47 ${ }^{\text {phox }}$, and $\mathrm{p} 67^{\mathrm{phox}}$, have been localized to type I cells by immunocytochemical staining (Kummer and Acker, 1995). The spectral absorption studies of Acker and his colleagues have enhanced the Nox hypothesis by showing that hypoxia reduces an isoform of cytochrome b558 (Lahiri et al., 1999). Also, a specific Nox inhibitor, 4-(2-aminoethyl)-benzenesulfonyl fluoride (AEBSF), was shown to first excite carotid sinus nerve activity, and then block the chemorecptor response to hypoxia (Lahiri et al., 1999).

Opposing these findings are multiple observations which question the validity of the NADPH oxidase hypothesis of chemotransduction. First, studies in the rat have shown that the heme-binding molecule, carbon monoxide ( $\mathrm{CO}$ ), activates $\mathrm{K}^{+}$-channels, and blocks the inhibitory effects of hypoxia, suggesting that a heme-protein physically associated with channel protein mediates the effects of hypoxia on channel activity (Lopez-Lopez and Gonzalez, 1992). Second, although early studies demonstrated that maxiK and TASK-like channels fail to respond to hypoxia following excision of membrane patches from type I cells (Wyatt and Peers, 1995; Buckler, 1999), more recent studies have obtained opposite results indicating that cytosolic factors (i.e., subunits of Nox) are not required for low- $\mathrm{O}_{2}$ inhibition of the $\mathrm{K}^{+}$-current (Riesco-Fagundo et al., 2001). Third, studies by Gonzalez and his colleagues showed that inhibitors of Nox (neopterin and arsine oxide) did not promote catecholamime (CA) release from the normoxic carotid body, nor block hypoxia-evoked CA release, indicating that $\mathrm{O}_{2}$-sensing in type $\mathrm{I}$ cells is not dependent on Nox function (Obeso et al., 1999). Fourth, although physiological hypoxia increases $\mathrm{NAD}(\mathrm{P}) \mathrm{H}$ levels in type I cell mitochondria (Duchen and Biscoe, 1992), it does not change the primary factor controlling the cytosolic redox state, namely, the reduced-to-oxidized glutathione (GSH/GSSH) ratio; moreover, pharmacological manipulation of the redox environment is not correlated with chemoreceptor excitation (Gonzalez et al., 2004, 2002). Finally, experiments using genetically modified mice lacking the gp91 ${ }^{\text {phox }}$ subunit (targeted gene deletion: knockout, $\mathrm{KO}$ ) demonstrated normal inhibition of $I_{\mathrm{K}}$ by hypoxia in type I cells, as well as normal hypoxia-evoked $\mathrm{Ca}^{2+}$-responses and CSN activity (He et al., 2002; Roy et al., 2000). On the other hand, mice lacking $\mathrm{p} 47^{\text {phox }}$ displayed an enhanced electrophysiological chemoreceptor response to hypoxia (Sanders et al., 2002). Thus, inhibiting Nox function via $47^{\text {phox }}$ gene KO resulted in an outcome (enhanced CSN response) which is diametrically opposed to findings obtained with the Nox inhibitor

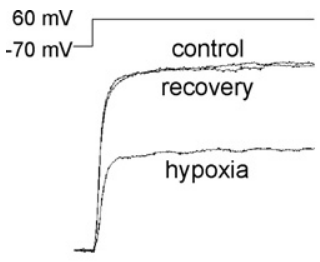

(A)

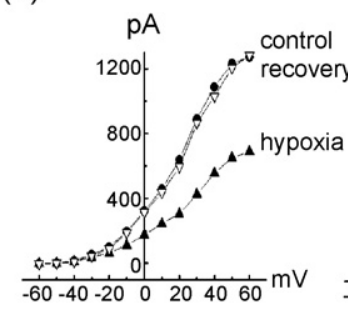

(C)

Normal

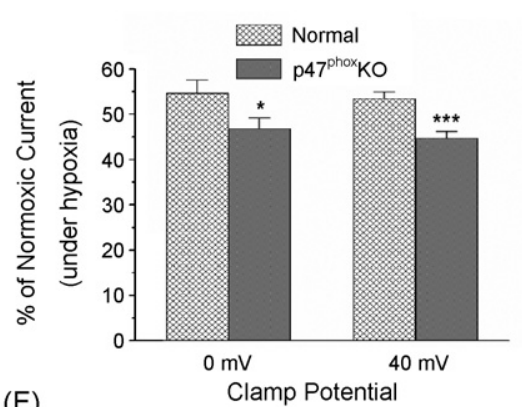

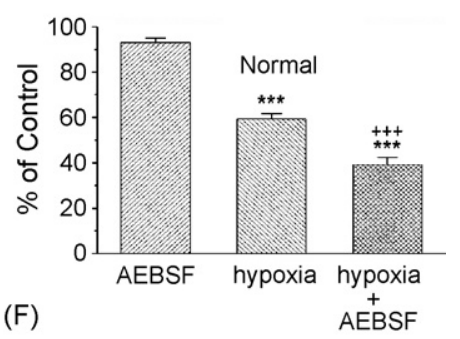
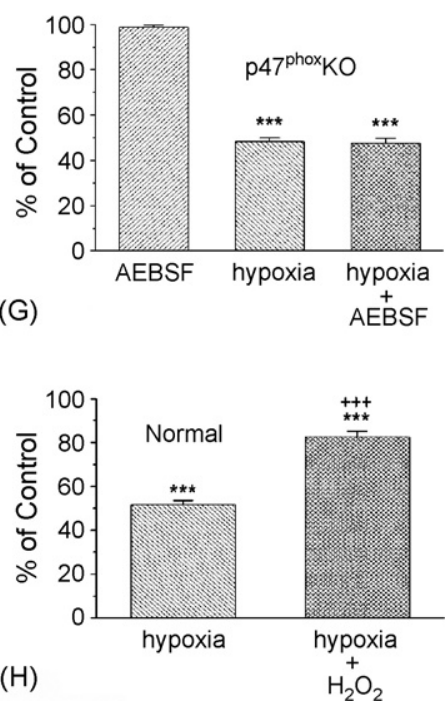

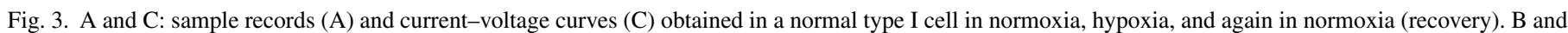

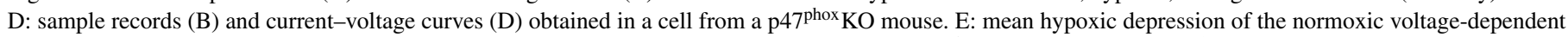

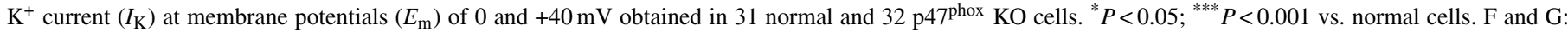

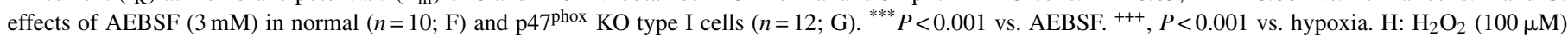

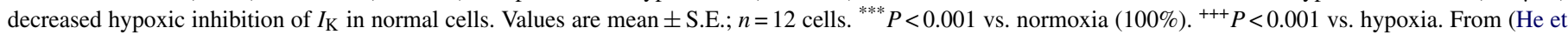
al., 2005) with permission. 

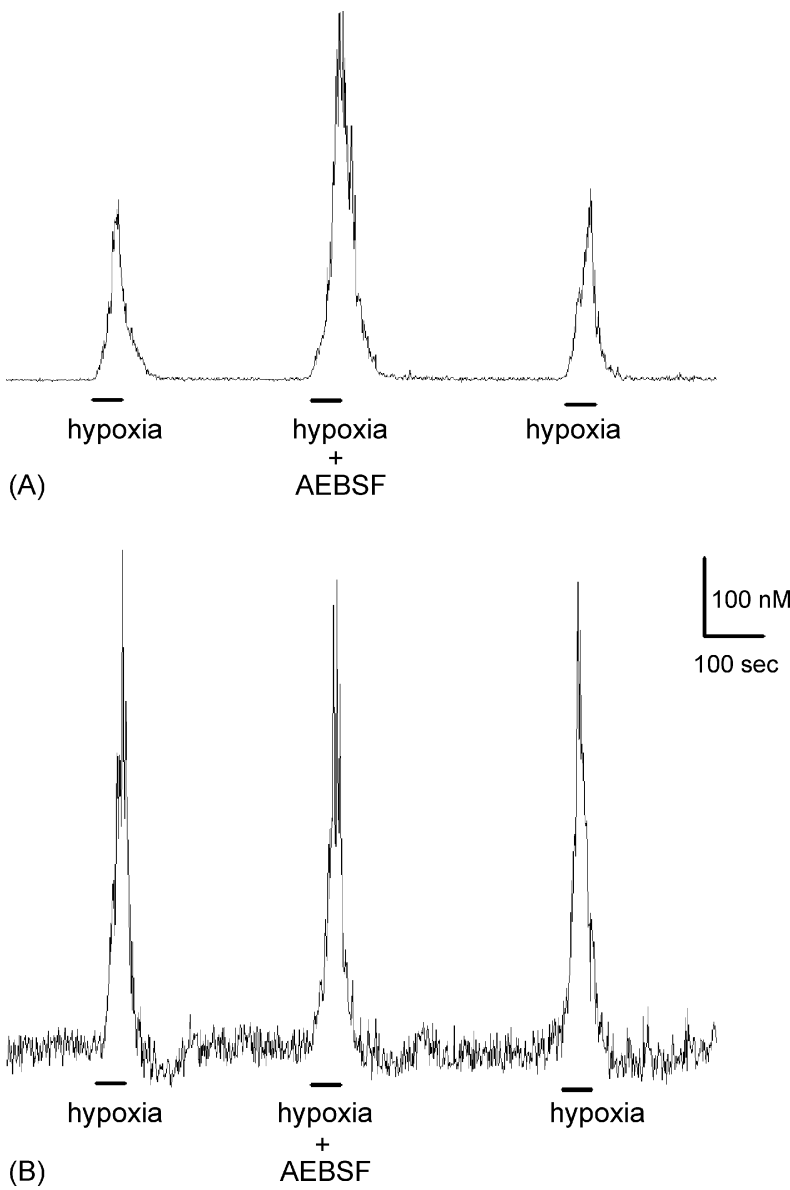

Fig. 4. Hypoxia-evoked $\mathrm{Ca}^{2+}$-responses in Fura-2-loaded mouse type I cells. (A) Response in normal cell is potentiated in presence of a specific Nox inhibitor, 4-(2-aminoethyl)-benzenesulfonyl fluoride (AEBSF; $3 \mathrm{mM}$ ). (B) In a cell from a $47^{\text {phox }}$ KO mouse, hypoxia evokes a larger response; however, AEBSF has no effect, consistent with the absence of functioning Nox.

AEBSF (absence of CSN response), albeit in different species. On the other hand, the finding that chemosensitivity is elevated in the absence of the cytosolic subunit, p47 $7^{\text {phox }}$, but remains unaltered following KO of gp91 ${ }^{\text {phox }}$ indicates that type I cells express a non-phagocyte isoform of Nox.

\section{Chemoreceptor function in normal and Nox-gene-deleted cells}

These controversial issues led us to focus further studies on whether the enhanced chemoreceptor discharge following $\mathrm{p} 47^{\text {phox }}$ gene-deletion reflected an underlying negative modulation of type I cells by Nox-generated ROS. In patch-clamp experiments greater than $70 \%$ of the voltage-dependent current in mouse type I cells was sensitive to iberiotoxin, consistent with the presence of large conductance maxiK channels (He et al., 2005). Moreover, we found that application of $\mathrm{H}_{2} \mathrm{O}_{2}$ decreased hypoxic inhibition of voltage-dependent $\mathrm{K}^{+}$-currents in normal mouse type I cells (Fig. 3), a result that agreed with previous studies of rat NEB cells and their analog, the H146cell-line (O'Kelly et al., 2000). In accord with Nox-mediated negative modulation, hypoxia-evoked depression of the maxiK-like current was greater in the $\mathrm{p} 47^{\text {phox }} \mathrm{KO}$ model, and the Nox inhibitor, AEBSF, enhanced hypoxia-induced current depression in normal, but not KO type I cells (Fig. 3). Studies of $\mathrm{Ca}^{2+}$-levels in type I cells further showed that basal and hypoxia-evoked $\left[\mathrm{Ca}^{2+}\right]_{\mathrm{I}}$ was higher in Nox-gene-deleted cells, and that AEBSF enhanced $\mathrm{Ca}^{2+}$-responses in normal, but not $\mathrm{KO}$ type I cells $(\mathrm{He}$ et al., 2005) (Fig. 4). In new experiments we have found that AEBSF enhances hypoxia-evoked CSN activity in the rat carotid body (Fig. 5), a result which conflicts with earlier studies (Lahiri et al., 1999). Collectively, these recent findings strongly suggest that ROS generated by Nox enhance maxiK-like currents, and promote cell repolarization. The data further confirm that hypoxia-induced depression of the voltage-sensitive $\mathrm{K}^{+}$-current occurs independently of Nox function.

A hypothetical scheme has emerged in which ROS levels increase in hypoxia, in a mechanism which opposes the excitatory effects of low- $\mathrm{O}_{2}$. Testing this idea required direct evaluation of the effects of hypoxia on ROS generation in type I cells. Experimental conditions for measuring ROS were established using mouse polymorphonuclear (PMN) cells loaded with the dye, dihydroethidium (DHE), which is oxidized by $\mathrm{O}_{2}{ }^{-}$to fluorescent ethidium. Normal mouse PMN displayed a rapid increase in fluorescence when stimulated with a cocktail consisting of the chemotactic peptide $N$ formyl-Met-Leu-Phe
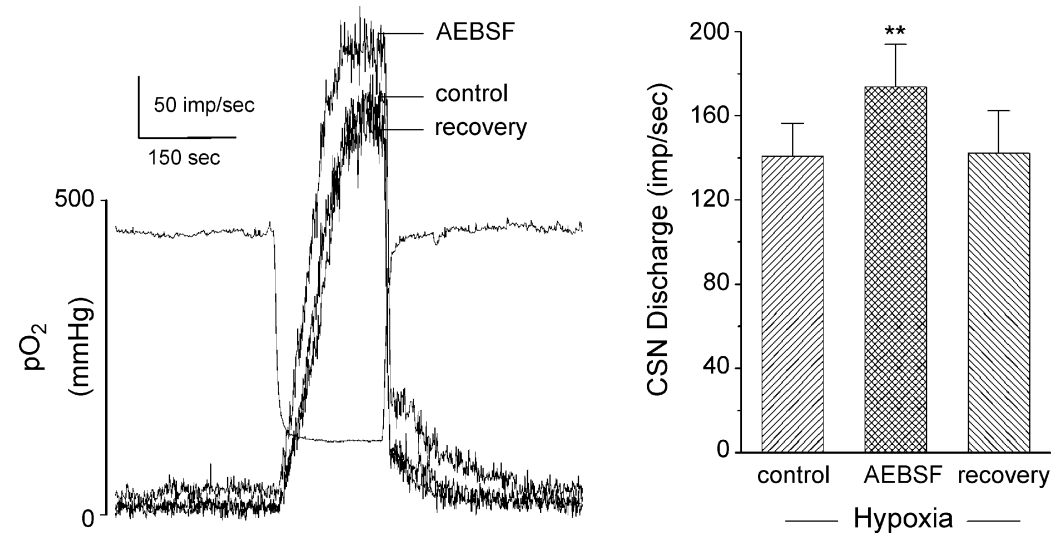

Fig. 5. Effect of specific Nox inhibitor, AEBSF $(3 \mathrm{mM})$ on rat carotid sinus nerve (CSN) activity evoked by acute hypoxia. In vitro superfused preparation. Left panel shows three superimposed traces of integrated nerve activity. Separate record indicates bath $\mathrm{P}_{\mathrm{O}_{2}}$. Right panel summarizes data from four preparations, and demonstrates significant $(P<0.01)$ enhancement of hypoxia-evoked response in presence of AEBSF. 


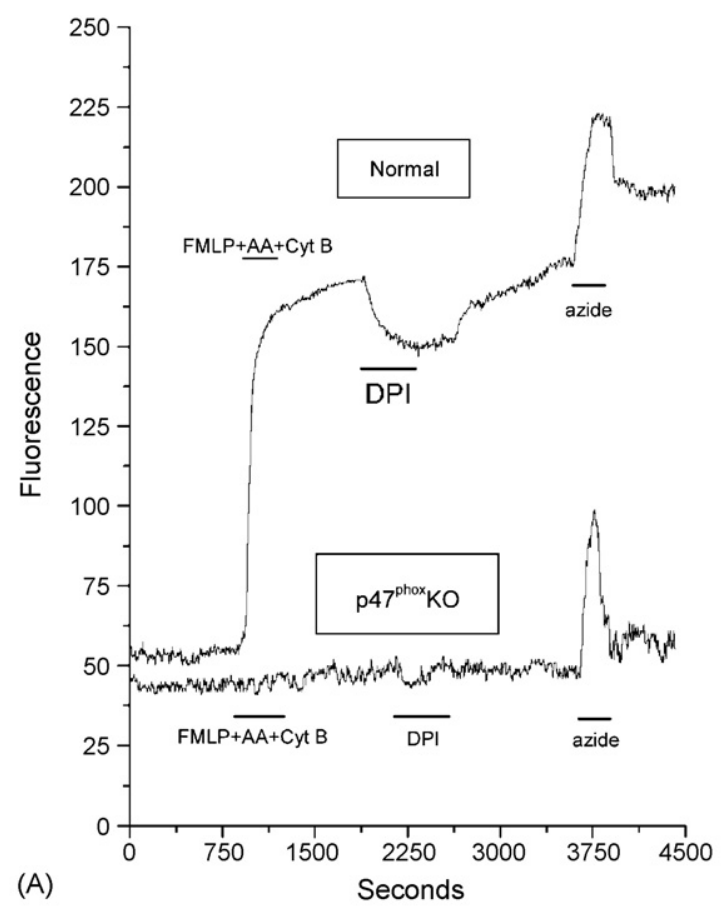

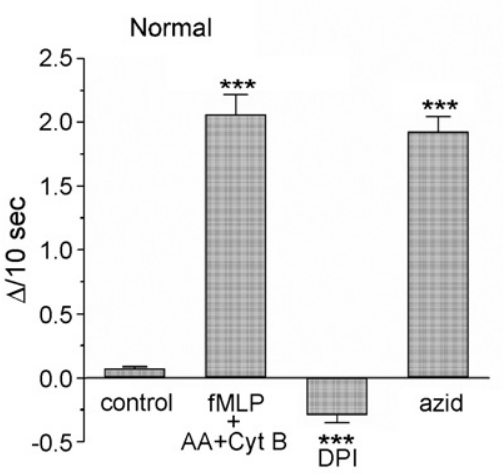

(B)

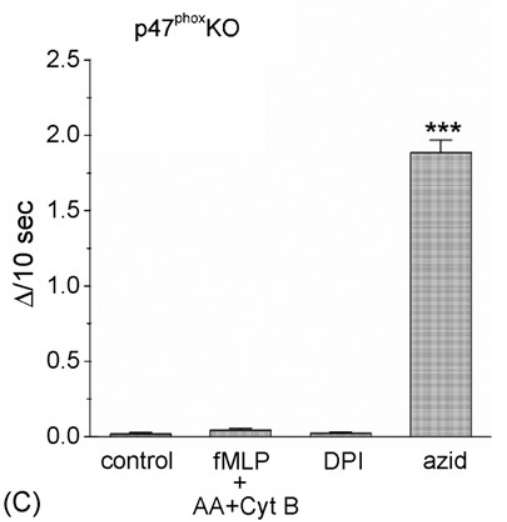

Fig. 6. A: a cocktail of neutrophil-stimulating agents [ $N$-formyl-Met-Leu-Phe (fMLP peptide; $1 \mu \mathrm{M})$, arachidonic acid (AA; $10 \mu \mathrm{M})$, and cytochalasin B (CytB; $5 \mu \mathrm{g} / \mathrm{ml}$ )] produced a sharp increase in dihydroethidium (DHE) fluorescence in a single attached polymorphonuclear neutrophil (PMN) from a normal mouse and no response in a p47 phox knockout (KO) PMN. Diphenyleneiodonium (DPI; $10 \mu \mathrm{M}$ ) decreased the fluorescence signal in the normal mouse and had no effect on the $47^{\text {phox }}$ KO PMN. Azide $(5 \mu \mathrm{M})$ caused a similar increase in fluorescence in the normal and $\mathrm{p}^{\mathrm{phox}} \mathrm{KO}$ PMN. B and C: summaries of DHE fluorescence for 98 normal (B) and $185 \mathrm{p} 47^{\text {phox }} \mathrm{KO}$ PMN (C). Data are expressed as slopes of fluorescence intensity change $(\Delta I / 10 \mathrm{~s})$ during the initial $100 \mathrm{~s}$ of the experimental conditions designated in A. ${ }^{* * *} P<0.001$ vs. drug-free conditions. From (He et al., 2005) with permission.

(fMLP; $1 \mu \mathrm{M}$ ), arachidonic acid (AA; $10 \mu \mathrm{M}$ ), and cytochalasin $\mathrm{B}(\mathrm{CB} ; 5 \mu \mathrm{g} / \mathrm{ml})$. This response was blocked by the Nox inhibitor diphenyleneiodonium (DPI, $10 \mu \mathrm{M}$ ) (He et al., 2005) (Fig. 6). The mitochondrial uncoupler, azide $(5 \mu \mathrm{M})$, also elicited a substantial increase in cell fluorescence. PMN from $\mathrm{p} 47^{\text {phox }} \mathrm{KO}$ mice did not respond to the cocktail, but did fluoresce like normal cells when treated with azide. The metabolic uncoupler also elicited a large increase in fluorescence in normal and $\mathrm{p} 47^{\text {phox }}$ KO type I cells, but when stimulated by hypoxia, only normal type I cells generated an AEBSF-sensitive response, indicating increased production of $\mathrm{O}_{2}{ }^{-}$originating from Nox (He et al., 2005) (Fig. 7). We have since reported similar results in rat carotid body lending further support to the hypothesis that low levels of $\mathrm{O}_{2}$ activate a unique form of Nox in type I cells (He et al., 2006). Because hypoxia has been shown to lower ROS levels in the H146 cell-line, in accord with a primary role for Nox in $\mathrm{O}_{2}$-sensing (O'Kelly et al., 2000), the data strongly indicate that hypoxia triggers opposite effects with respect to Nox activation in carotid body versus airway chemoreceptors.

The finding that ROS generation increases as $\mathrm{O}_{2}$ levels decrease may appear as overtly counterintuitive to fundamental concepts of enzyme-substrate interactions. However, the affinity of the type I cell Nox isoform for $\mathrm{O}_{2}$ is unknown, and the reported mean $K_{\mathrm{m}}$ for $\mathrm{O}_{2}$ of phagocyte Nox is $\mathrm{P}_{\mathrm{O}_{2}}=12.7$ Torr (Cross and Jones, 1986), about half of $\mathrm{P}_{\mathrm{O}_{2}}$ used to stimulate ROS production (He et al., 2005). Thus in physiological hypoxia, $\mathrm{O}_{2}$ availability may not limit Nox activity. In fact, the phagocyte Nox is adapted to function in naturally hypoxic conditions, including wounds. On the other hand, a potentially relevant factor for Nox activation is the cellular concentration of enzyme cofactor, NADPH. In a 

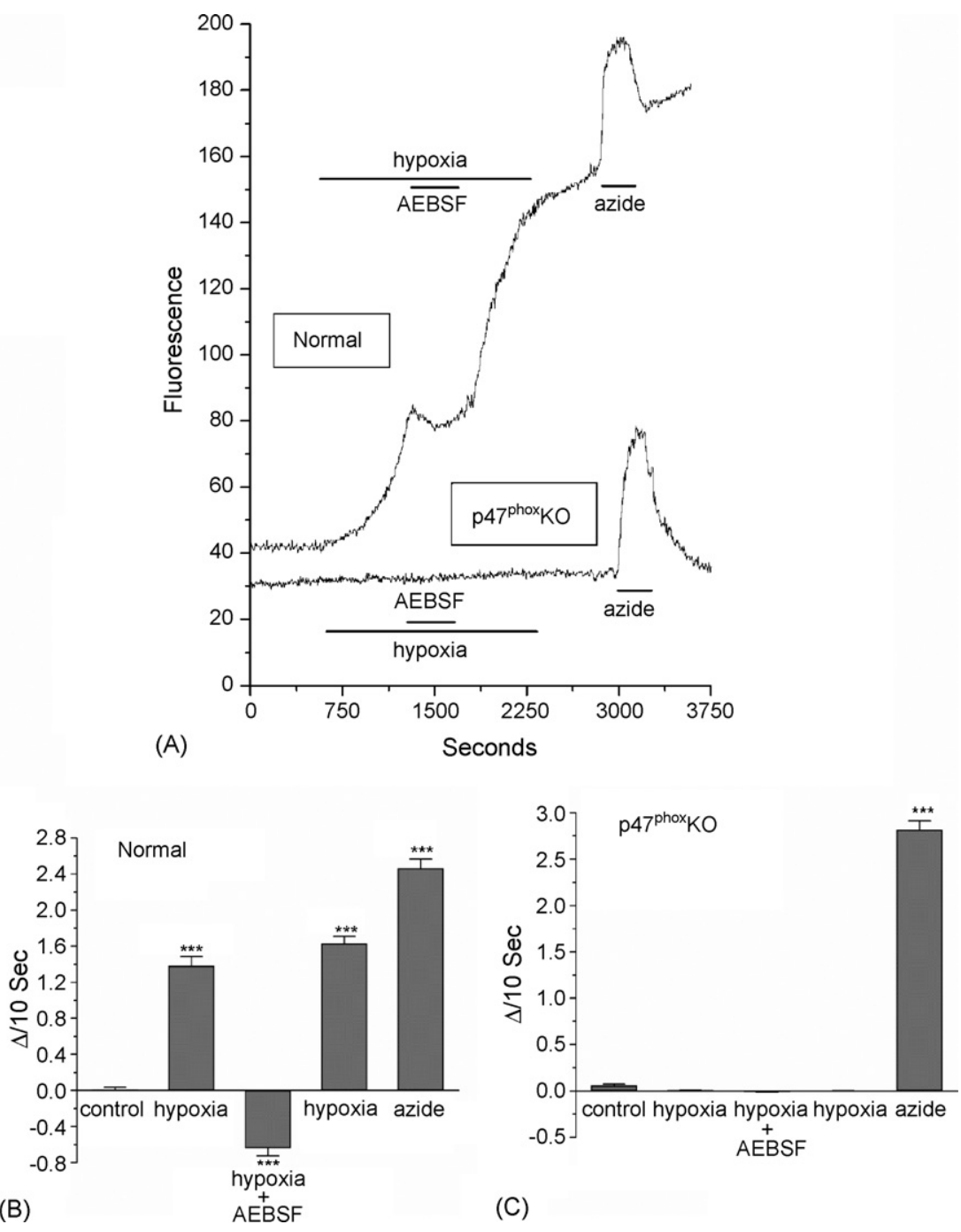

(C)

Fig. 7. A: effect of hypoxia on DHE fluorescence in carotid body type I cells isolated from normal and p47phox KO mice. In normoxia, fluorescence gradually increases and is markedly elevated by hypoxia in the normal but not in the p47 ${ }^{\text {phox }} \mathrm{KO}$ cell. 4-(2-Aminoethyl)-benzenesulfonyl fluoride (AEBSF; $3 \mathrm{mM}$ ) depresses hypoxic increase of reactive oxygen species (ROS) production in the normal type I cell. Azide ( $5 \mu \mathrm{M})$ increased the fluorescence in the normal and p47phox KO cells. $\mathrm{B}$ and C: summaries of DHE fluorescence for 32 normal (B) and $44 \mathrm{p} 47^{\mathrm{phox}} \mathrm{KO}$ type I cells (C) harvested from four normal and four KO animals. Slopes ( $\left.\Delta I / 10 \mathrm{~s}\right)$ were quantified as described in Fig. $6 .{ }^{* * *} P<0.001$ vs. control, normoxic conditions. From (He et al., 2005) with permission.

previous study we demonstrated that hypoxia increases ouabainsensitive glucose uptake in carotid body type I cells (Obeso et al., 1993). This finding is consonant with the hypothesis that hypoxia-evoked cell depolarization activates $\mathrm{Na}^{+} / \mathrm{K}^{+}$-ATPase, thereby triggering metabolic flux of glucose through the HMS. The resulting increase of cofactor could thus be responsible for activation of Nox after the initial hypoxia-induced depolarization. In preliminary experiments, we have found support for this scheme by showing that inhibitors of the HMS (epiandrosterone, 6-aminonicotinomide) block hypoxia-induced ROS production in rat type I cells, and enhance hypoxia-evoked CSN activity.

\section{Summary: adaptation of Nox isoforms in airway versus arterial chemoreceptor cells}

Nox isoforms are present in airway (NEB) and arterial (carotid body) chemoreceptos where they subserve diverse signaling functions (Kummer and Acker, 1995; Youngson et al.,
1997). In NEB, Nox appears to be a primary $\mathrm{O}_{2}$-sensor which produces ROS in proportion to local $\mathrm{P}_{\mathrm{O}_{2}}$. $\mathrm{K}^{+}$-currents are activated by $\mathrm{H}_{2} \mathrm{O}_{2}$, and pharmacological inhibition of Nox partially blocks low- $\mathrm{O}_{2}$ depression of currents (O'Kelly et al., 2000, 2001; Fu et al., 2000b). Gene-deletion of the phagocyte gp91 $1^{\text {phox }}$ subunit (Nox2), inhibits responses to low- $\mathrm{O}_{2}$ (Fu et al., 2000a). Finally, detailed studies of the NEB analog cell-line (H146) suggest that Nox-mediated $\mathrm{O}_{2}$-sensing may be only one of multiple mechanisms detecting $\mathrm{O}_{2}$ in airway chemoreceptor cells (O'Kelly et al., 2001).

In arterial chemoreceptor type I cells, the available data indicate that primary $\mathrm{O}_{2}$-sensing occurs via a membrane-delimited (but also see Buckler, 1999; Wyatt and Peers, 1995) detector which responds to a decrease in $\mathrm{P}_{\mathrm{O}_{2}}$ by closure of $\mathrm{K}^{+}$-channels (Riesco-Fagundo et al., 2001). Cell depolarization activates voltage-dependent $\mathrm{Ca}^{2+}$-channels and exocytotic release of neurotransmitters. Unlike NEB cells, functional Nox is not necessary for the full expression of $\mathrm{O}_{2}$-sensing in type I cells. 
Nox gene-deletion $\left(\mathrm{p} 47^{\text {phox }}\right)$ in fact enhances chemoreceptor sensitivity, consistent with a modulatory role for ROS. This conclusion is supported by studies of voltage-sensitive $\mathrm{K}^{+}$-currents, cell $\mathrm{Ca}^{2+}$-responses, and measurement of ROS production in type I cells. Data from the normal versus $\mathrm{p} 47^{\text {phox }} \mathrm{KO}$ mice, and rats, uniformly indicate that hypoxia activates Nox-dependent ROS production, and that ROS increase voltage-dependent $\mathrm{K}^{+}$currents, thereby promoting cell repolarization. Importantly, the primary $\mathrm{O}_{2}$-sensing machinery in type I cells appears to be insensitive to the cytosolic redox state. Moreover, hypoxia does not alter the cytosolic GSH/GSSH redox potential in carotid body, suggesting that changes in the redox status are confined to microdomains closely associated with target molecules (Gonzalez et al., 2002, 2004). Consistent with this conclusion is a recent report showing that co-expression of TASK- $1 \mathrm{~K}^{+}$channels and Nox4 in HEK293 cells results in association in the plasma membrane (Lee et al., 2006).

\section{Perspectives and future directions}

The Nox model of $\mathrm{O}_{2}$-sensing as originally formulated by Acker and his colleagues (Acker et al., 1989; Cross et al., 1990) stimulated numerous studies which elucidated novel mechanisms involving ROS in cellular and systemic responses to hypoxia (Acker, 2005). Compelling evidence for Nox-mediated $\mathrm{O}_{2}$-sensing has been obtained in NEB, and ROS have been implicated in regulating ion channel activity and gene expression in multiple cells and tissues (Acker, 2005). In the carotid body available evidence suggests that Nox fills a unique supporting role as a modulator of type I cell activity. However, several issues remain which require further investigation for complete understanding of Nox involvement in arterial chemoreception. Of paramount importance is the identification of the Nox isoform expressed in type I cells, and detailed examination of the role of NADPH cofactor in regulating ROS production. To this end, it will be important to examine the relationship between glucose uptake and cofactor production in the HMS. It is encouraging that recent studies of pulmonary versus coronary vascular smooth muscle have shown that inherently different levels of ROS production by Nox 4 are correlated with cellular concentrations of NADPH (Gupte et al., 2005).

Although our data strongly support a role for ROS in the enhancement of maxiK currents in type I cells, virtually nothing is known about the influence of ROS on TASK-like channel activity in carotid body. This is particularly important in view of the fact that these $\mathrm{O}_{2}$-sensitive channels appear to control type I cell $\mathrm{E}_{\mathrm{M}}$ via a background leak current (Buckler, 1999; Buckler et al., 2000). Importantly, a study of TASK-1 channels co-expressed in HEK293 cells along with Nox4 showed that background $\mathrm{K}^{+}$-current was correlated with Nox activity (Lee et al., 2006). Thus, hypoxia-initiated ROS production may promote type I cell recovery via both maxiK and TASK-like channels. Although not fully understood, recent findings indicate that hypoxia inhibits TASK-1 and TASK-3 in type I cells via changes in mitochondrial energy metabolism, perhaps involving cytosolic concentrations of ATP (Buckler et al., 2006).
A final important consideration is the role of Nox in adaptation of the carotid body during chronic exposure to hypoxia. It has been repeatedly demonstrated that chronic hypoxia $(\mathrm{CH})$ elicits remarkable structural changes and chemosensory hypersensitivity in mammalian carotid body (Dinger et al., 2003). Moreover, systemic hypoxia is known to increase levels of ROS in tissues, consistent with increased $\mathrm{O}_{2}{ }^{-}$production in mitochondria (Chandel and Schumacker, 2000a) and/or via enhanced Nox activity. The finding that type I cell activity in acute hypoxia is routinely modulated by ROS suggests the possibility that Nox acts as an important regulatory mechanism which could limit $\mathrm{CH}$-induced hyperexcitability. In contrast, a different paradigm of prolonged exposure, namely, chronic intermittent hypoxia (CIH), has been shown to elicit chemoreceptor hypersensitivity involving cellular mechanisms which differ fundamentally from CH (Peng and Prabhakar, 2004). Interestingly, Prabhakar and his colleagues have demonstrated that ROS scavengers prevent the $\mathrm{CIH}$-induced increase in chemosensitivity (Peng and Prabhakar, 2003). Future studies may determine that diverse mechanisms involving Nox are critical for resetting chemosensitivity in carotid body following $\mathrm{CH}$ versus $\mathrm{CIH}$.

\section{Acknowledgements}

Supported by USPHS Grants NS 12636, NS 07938, NL-50153, and Spanish DGICYT (BFU2004-06394), FISS (PI042462) and JCyL (VA011C05).

\section{References}

Acker, H., 1994. Mechanisms and meaning of cellular oxygen sensing in the organism. Resp. Physiol. 95 (1), 1-10.

Acker, H., 2005. The oxygen sensing signal cascade under the influence of reactive oxygen species. Philos. Trans. R. Soc. Lond. B: Biol. Sci. 360, 2201-2210.

Acker, H., Bolling, B., Delpiano, M.A., Dafau, E., Gorlach, A., Holtermann, G., 1992. The meaning of $\mathrm{H}_{2} \mathrm{O}_{2}$ generation in carotid body cells for $\mathrm{PO}_{2}$ chemoreception. J. Auton. Nerv. Syst. 41 (1-2), 41-51.

Acker, H., Dufau, E., Huber, J., Sylvester, D., 1989. Indications to an NADPH oxidase as a possible $\mathrm{pO}_{2}$ sensor in the rat carotid body. FEB 256 (1-2), 75-78.

Babior, B.M., 1999. NADPH oxidase: an update. Blood 93 (5), 1464-1476.

Brar, S.S., Kennedy, T.P., Sturrock, A.B., Huecksteadt, T.P., Quinn, M.T., Murphy, T.M., Chitano, P., Hoidal, J.R., 2002a. NADPH oxidase promotes NF-кB activation and proliferation in human airway smooth muscle. Am. J. Physiol. Lung Cell. Mol. Physiol. 282, L782-L795.

Brar, S.S., Kennedy, T.P., Sturrock, A.B., Huecksteadt, T.P., Quinn, M.T., Whorton, A.R., Hoidal, J.R., 2002b. An NAD(P)H oxidase regulates growth and transcription in melanoma cells. Am. J. Physiol. Cell. Physiol. 282, C1212-C1224.

Buckler, K.J., 1997. A novel oxygen-sensitive potassium current in rat carotid body type I cells. J. Physiol. 498 (3), 649-666.

Buckler, K.J., 1999. Background leak $\mathrm{K}^{+}$-currents and oxygen sensing in carotid body type 1 cells. Resp. Physiol. 115, 179-187.

Buckler, K.J., Williams, B.A., Honore, E., 2000. An oxygen-, acid- and anaesthetic-sensitive TASK-like background potassium channel in rat arterial chemoreceptor cells. J. Physiol. 525 (1), 135-142.

Buckler, K.J., Williams, B.A., Orozco, R.V., Wyatt, C.N., 2006. The role of TASK-like $\mathrm{K}+$ channels in oxygen sensing in the carotid body. Novart. Found. Symp. 272, 73-85.

Chandel, N.S., Schumacker, P.T., 2000b. Cellular oxygen sensing by mitochondria: old questions, new insight. J. Appl. Physiol. 88, 1880-1889. 
Chandel, N.S., Schumacker, P.T., 2000a. Cellular oxygen sensing by mitochondria: old questions, new insight. J. Appl. Physiol. 88, 1880-1889.

Cheng, G., Cao, Z., Xu, X., Van Meir, E.G., Lambeth, J.D., 2001. Homologs of gp91phox: cloning and tissue expression of Nox3, Nox4 and Nox5. Gene $269,131-140$

Cross, A.R., Henderson, L., Jones, O.T.G., Delpiano, M.A., Hentschel, J., Acker, $\mathrm{H} ., 1990$. Involvement of an $\mathrm{NAD}(\mathrm{P}) \mathrm{H}$ oxidase as a $\mathrm{pO}_{2}$ sensor protein in the rat carotid body. Biochem. J. 272, 743-747.

Cross, A.R., Jones, O.T.G., 1986. The effect of the inhibitor diphenylene iodonium on the superoxide-generating system of neutrophils. Biochem. J. 237, 111-116.

Diebold, B.A., Bokoch, G.M., 2001. Molecular basis for Rac2 regulation of phagocyte NADPH oxidase. Nat. Immunol. 2 (3), 211-215.

Dinger, B., He, L., Chen, J., Stensaas, L., Fidone, S., 2003. Mechanisms of morphological and functional plasticity in the chronically hypoxic carotid body. In: Lahiri, S., Semenza, G., Prabhakar, N. (Eds.), Oxygen Sensing: Responses and Adaptation to Hypoxia. Marcel Dekker, New York, pp. 439-465.

Donnelly, D.F., 1997. Are oxygen dependent $\mathrm{K}^{+}$channels essential for carotid body chemo-transduction? Resp. Physiol. 110, 211-218.

Duchen, M.R., Biscoe, T.J., 1992. Mitochondrial function in type I cells isolated from rabbit arterial chemoreceptors. J. Physiol. 450, 13-31.

Fidone, S., Dinger, B.G., Gonzalez, C., 1995. Mechanisms of carotid body chemoreception. In: Dempsey, J.A., Pack, A.I. (Eds.), The Lung Biology in Health Disease, vol. X, The Regulation of Breathing. Marcel Dekker Inc., New York, pp. 391-471.

Fidone, S.J., Gonzalez, C., Almaraz, L., Dinger, B., 1997. Cellular mechanisms of peripheral chemoreceptor function. In: Crystal, R.G., West, J.B., et al. (Eds.), The Lung: Scientific Foundations. Lippincott-Raven Publishers, Philadelphia, pp. 1725-1746.

Finkel, T., 2000. Redox-dependent signal transduction. FEBS Lett. 476, 52-54.

Fu, X.W., Wang, D., Nurse, C.A., Dinauer, M.C., Cutz, E., 2000a. NADPH oxidase is an $\mathrm{O}_{2}$ sensor in airway chemoreceptors: evidence from $\mathrm{K}^{+}$current modulation in wild-type and oxidase-deficient mice. PNAS 97 (8), 4374-4379.

Fu, X.-W., Wang, D., Nurse, C.A., Dinauer, M.C.C.E., 2000b. NADPH oxidase is an $\mathrm{O}_{2}$ sensor in airway chemoreceptors: evidence from $\mathrm{K}^{+}$current modulation in wild-type and oxidase-deficient mice. PNAS 97 (8), 4374-4379.

Gonzalez, C., Almaraz, L., Obeso, A., Rigual, R., 1994. Carotid body chemoreceptors: from natural stimuli to sensory discharges. Physiol. Rev. 74, 829-898.

Gonzalez, C., Sanz-Alfayate, G., Agapito, M.T., Gomez-Nino, A., Rocher, A., Obeso, A., 2002. Significance of ROS in oxygen sensing in cell systems with sensitivity to physiological hypoxia. Resp. Physiol. Neurobiol. 132, 17-41.

Gonzalez, C., Sanz-Alyayate, G., Agapito, M.T., Obeso, A., 2004. Effects of reducing agents on glutathione metabolism and the function of carotid body chemoreceptor cells. Biol. Chem. 385, 265-274.

Görlach, A., Diebold, I., Schini-Kerth, V.P., Berchner-Pfannschmidt, U., Roth, U., Brandes, R.P., Kietzmann, T., Busse, R., 2001. Thrombin activates the hypoxia-inducible factor-1 signaling pathway in vascular smooth muscle cells: role of the p22 ${ }^{\text {phox }}$-containing NADPH oxidase. Circ. Res. 89, 47-54.

Griendling, K.K., Sorescu, D., Ushio-Fukai, M., 2000. NAD(P)H oxidase: role in cardiovascular biology and disease. Circ. Res. 86, 494-501.

Gupte, S.A., Kaminski, P.M., Floyd, B., Agarwal, R., Ali, N., Ahmad, M., Edwards, J., Wolin, M.S., 2005. Cytosolic NADPH may regulate differences in basal Nox oxidase-derived superoxide generation in bovine coronary and pulmonary arteries. Am. J. Physiol. Heart Circ. Physiol. 288, H13$\mathrm{H} 21$.

He, L., Chen, J., Dinger, B., Sanders, K., Sundar, K., Hoidal, J., Fidone, S., 2002. Characteristics of carotid body chemosensitivity in NADPH oxidasedeficient mice. Am. J. Physiol. Cell. Physiol. 282, C27-C33.

He, L., Dinger, B., Gonzalez, C., Obeso, A., Fidone, S., 2006. Function of NADPH oxidase and signaling by reactive oxygen species in rat carotid body type I cells. Adv. Exp. Med. Biol. 580, 155-160.

He, L., Dinger, B., Sanders, K., Hoidal, J., Obeso, A., Stensaas, L., Fidone, S., Gonzalez, C., 2005. Effect of p47phox gene deletion on ROS production and oxygen sensing in mouse carotid body chemoreceptor cells. Am. J. Physiol. Lung Cell. Mol. Physiol. 289, L916-L924.
Hoshi, T., Heinemann, S.H., 2001. Topical review: regulation of cell function by methionine oxidation and reduction. J. Physiol. 531 (1), 1-11.

Irani, K., 2000. Oxidant signaling in vascular cell growth, death and survival: a review of the roles of reactive oxygen species in smooth muscle and endothelial cell mitogenic and apoptotic signaling. Circ. Res. 87, 179-183.

Kummer, W., Acker, H., 1995. Immunohistochemical demonstration of four subunits of neutrophil NAD(P)H oxidase in type I cells of carotid body. J. Appl. Physiol. 78 (5), 1904-1909.

Lahiri, S., Ehleben, W., Acker, H., 1999. Chemoreceptor discharges and cytochrome redox changes of the rat carotid body: role of heme ligands. Proc. Natl. Acad. Sci. U.S.A. 96, 9427-9432.

Lambeth, J.D., 2002. Nox/Duox family of nicotinamide adenine dinucleotide (phosphage) oxidases. Curr. Opin. Hematol. 9, 11-17.

Lee, Y.M., Kim, B.J., Chun, Y.S., So, I., Choi, H., Kim, M.S., Park, J.W., 2006. NOX4 as an oxygen sensor to regulate TASK-1 activity. Cell Signal 18, 499-507.

Li, J.-M., Shah, A.J., 2002. Intracellular localization and preassembly of the NADPH oxidase complex in cultured endothelial cells. J. Biol. Chem. 277 (22), 19952-19960.

Lopez-Barneo, J., 1994. Oxygen-sensitive ion channels: how ubiquitous are they? TINS 17 (4), 133-135.

Lopez-Barneo, J., Pardal, R., Ortega-Saenz, P., 2001. Cellular mechanism of oxygen sensing. Annu. Rev. Physiol. 63, 259-287.

Lopez-Lopez, J., Gonzalez, C., Urena, J., Lopez-Barneo, J., 1989. Low $\mathrm{PO}_{2}$ selectively inhibits $\mathrm{K}^{+}$channel activity in chemoreceptor cells of the mammalian carotid body. J. Gen. Physiol. 93, 1001-1015.

Lopez-Lopez, J.R., Gonzalez, C., 1992. Time course of $\mathrm{K}^{+}$current inhibition by low oxygen in chemoreceptor cells of adult rabbit carotid body: effects of carbon monoxide. FEBS Lett. 299, 251-254.

Michelakis, E.D., Hampl, V., Nsair, A., Wu, X.C., Harry, G., Haromy, A., Gurtu, R., Archer, S.L., 2002. Diversity in mitochondrial function explains differences in vascular oxygen sensing. Circ. Res. 90, 1307-1315.

O'Kelly, I., Lewis, A., Peers, C., Kemp, P.J., 2000. O $_{2}$ sensing by airway chemoreceptor-derived cells: protein kinase $\mathrm{C}$ activation reveals functional evidence for involvement of NADPH oxidase. J. Biol. Chem. 275 (11), 7684-7692.

O'Kelly, I., Peers, C., Kemp, P.J., 2001. NADPH oxidase does not account fully for $\mathrm{O}_{2}$-sensing in model airway chemoreceptor cells. Biochem. Biophys. Res. Commun. 283, 1131-1134.

Obeso, A., Gomez-Nino, A., Gonzalez, C., 1999. NADPH oxidase inhibition does not interfere with low $\mathrm{PO}_{2}$ transduction in rat and rabbit $\mathrm{CB}$ chemoreceptor cells. Am. J. Physiol. 276 (Cell Physiol. 45), C593-C601.

Obeso, A., Gonzalez, C., Rigual, R., Dinger, B., Fidone, S., 1993. Effect of low $\mathrm{O}_{2}$ on glucose uptake in rabbit carotid body. J. Appl. Physiol. 74 (5), 2387-2393.

Pani, G., Bedogni, B., Colavitti, R., Anezvino, R., Borrello, S., Galeotti, T., 2001. Cell compartmentalization in redox signaling. IUBMB Life 52, 7-16.

Patel, A.J., Honoré, E., 2001. Molecular physiology of oxygen-sensitive potassium channels. Eur. Resp. J. 18, 221-227.

Peers, C., 1990. Hypoxic suppression of $\mathrm{K}^{+}$currents in type I carotid body cells: selective effect on the $\mathrm{Ca}^{2+}$-activated $\mathrm{K}^{+}$current. Neurosci. Lett. 119, 253-256.

Peers, C., Buckler, K.J., 1995. Transduction of chemostimuli by the type I carotid body cell. J. Membr. Biol. 144, 1-9.

Peng, Y.J., Prabhakar, N.R., 2003. Reactive oxygen species in the plasticity of respiratory behavior elicited by chronic intermittent hypoxia. J. Appl. Physiol. 94, 2342-2349.

Peng, Y.J., Prabhakar, N.R., 2004. Effect of two paradigms of chronic intermittent hypoxia on carotid body sensory activity. J. Appl. Physiol. 96, 1236-1242.

Porwol, T., Ehleben, W., Brand, V., Acker, H., 2001. Tissue oxygen sensor function of NADPH oxidase isoforms, and an unusual cytochrome aa3; producing reactive oxygen species. Resp. Physiol. 128, 331-348.

Prabhakar, N.R., 2000. Oxygen sensing by the carotid body chemoreceptors. J. Appl. Physiol. 88, 2287-2295.

Riesco-Fagundo, A.M., Pérez-García, M.T., Gonzalez, C., López-López, J.R., 2001. $\mathrm{O}_{2}$ modulates large-conductance $\mathrm{Ca}^{2+}$-dependent $\mathrm{K}^{+}$channels of rat 
chemoreceptor cells by a membrane-restricted and CO-sensitive mechanism. Circ. Res. 89, 430-436.

Roy, A., Rozanov, C., Mokashi, A., Daudu, P., Al-mehdi, A.B., Shams, H., Lahiri, S., 2000. Mice lacking in gp91 phox subunit of NAD(P)H oxidase showed glomus cell $[\mathrm{Ca}(2+)](\mathrm{i})$ and respiratory responses to hypoxia. Brain Res. 872, 188-193.

Sanders, K.A., Sundar, K., He, L., Dinger, B., Fidone, S., Hoidal, J.R., 2002. Role of components of the phagocytic NADPH oxidase in oxygen sensing. J. Appl. Physiol. 93 (4), 1357-1364.

Sauer, H., Wartenberg, M., Hescheler, J., 2001. Reactive oxygen species as intracellular messengers during cell growth and differentiation. Cell. Physiol. Biochem. 11, 173-186.

Sylvester, J.T., 2001. Hypoxic pulmonary vasoconstriction: a radical view. Circ. Res. 88, 1228-1230.

Szöcs, K., Lassè, B., Sorescu, D., Hilenski, L.L., Valppu, L., Couse, T.L., Wilcox, J.N., Quinn, M.T., Lambeth, J.D., Griendling, K.K., 2002. Upregulation of Nox-based NAD $(\mathrm{P}) \mathrm{H}$ oxidases in restenosis after carotid injury. Arterioscler Thromb. Vasc. Biol. 22, 21-27.

Tang, X.D., Daggett, H., Hanner, M., Garcia, M.L., McManus, O.B., Brot, N., Weissbach, H., Heinemann, S.H., Hoshi, T., 2001. Oxidative regulation of large conductance calcium-activated potassium channels. J. Gen. Physiol. 117, 253-273.
Thannickal, V.J., Fanburg, B.L., 2000. Reactive oxygen species in cell signaling. Am. J. Physiol. Lung Cell. Mol. Physiol. 279, L1005-L1028.

Wang, D., Youngson, C., Wong, V., Yeger, H., Dinauer, M.C., Vega-Saenz De Miera, E., Rudy, B., Cutz, E., 1996. NADPH-oxidase and a hydrogen peroxide-sensitive $\mathrm{K}^{+}$channel may function as an oxygen sensor complex in airway chemoreceptors and small cell lung carcinoma cell lines. Proc. Natl. Acad. Sci. U.S.A. 93, 13182-13187.

Waypa, G.B., Chandel, N.S., Schumacker, P.T., 2001. Model for hypoxic pulmonary vasoconstriction involving mitochondrial oxygen sensing. Circ. Res. $88,1259-1266$.

Wilson, D.F., Mokashi, A., Chugh, D., Vinogradov, S., Osanai, S., Lahiri, S., 1994. The primary oxygen sensor of the cat carotid body is cytochrome $\alpha_{3}$ of the mitochondrial respiratory chain. FEBS Lett. 351, 370-374.

Wyatt, C.N., Peers, C., 1995. $\mathrm{Ca}^{2+}$-activated $\mathrm{K}^{+}$channels in isolated type I cells of the neonatal rat carotid body. J. Physiol. 483 (3), 559-565.

Xu, D., Rovira, I.I., Finkel, T., 2002. Oxidants painting the Cysteine Chapel: redox regulation of PTPs. Dev. Cell 2, 251-259.

Youngson, C., Nurse, C., Yeger, H., Curnutte, J.T., Vollmer, C., Wong, V., Cutz, E., 1997. Immunocytochemical localization on O2-sensing protein (NADPH oxidase) in chemoreceptor cells. Microsc. Res. Tech. 37, 101-106.

Zhu, H., Jackson, T., Bunn, H.F., 2002. Detecting and responding to hypoxia. Nephrol. Dial. Transplant. 17 (Suppl. 1), 3-7. 